\title{
CHANGES IN SCHOOL ANXIETY AND EMOTIONAL SELF-REGULATION OF AN ADOLESCENCE EXPERIMENTAL GROUP FOLLOWING THE ABKT-B PROGRAMME
}

\author{
Baiba Kalnciema \\ University of Latvia, Latvia \\ Guna Svence \\ University of Latvia, Latvia
}

\begin{abstract}
The purpose of this study was to adapt the experimental programme MBCT-C (Randy J. Semple \& Jennifer Lee's programme "Mindfulness-Based Cognitive Therapy for Anxious Children", 2011) in early adolescents and compare the changes in school anxiety and emotional regulation indicators before and after in the experimental and control group. The necessity for intervention with respect to school anxiety and emotional regulation among children with emotional regulation and school anxiety issues in the early adolescence group was indicated by research into problems connected with youth behaviour and difficulties in regulating emotions. The study analysed the results of six $6^{\text {th }}$ grade students (12-13 years old) using the following instruments: The Emotion Questionnaire (Rydell, Berlin, \& Bohlin, 2003, adapted by Grīvza, Brūdere-Ruska, \& Raikova, 2014); the School Anxiety Questionnaire (Beeman N. Phillips, 1970, translated by Zalcmane, 2004), the Parent Evaluation Questionnaire (Semple \& Lee, 2011) and the Children Evaluation Questionnaire (Semple \& Lee, 2011) that have been used in research as assessment instruments. Testing was performed in two stages: before intervention and after 12 intervention sessions. The experimental group showed an improvement in all school anxiety results compared to the control group, but the school anxiety results of control group pupils deteriorated. Emotional regulation indicators for both groups decreased, but the main impact of the experiment was demonstrating that after 12 intervention sessions the level of school anxiety dropped, while scores related to emotional awareness compared to the control group increased.
\end{abstract}

Keywords: mindfulness, MBCT-C (ABKT-B), emotional regulation, school anxiety, early adolescence.

\section{Introduction}

The MBCT-C programme (based on Mindfulness-Based Cognitive Therapy for Anxious Children (Semple \& Jennifer, 2011) helps to explain how symptoms of anxiety can manifest in thoughts, feelings, bodily sensations and behaviour. One of the main goals of the programme is to help adolescents become more aware of their thoughts, feelings and bodily sensations as separate, yet interrelated 
Kalnciema \& Svence, 2020. Changes in School Anxiety and Emotional Self-Regulation of an Adolescence Experimental Group Following the ABKT-B Programme

phenomena that work together to shape their perception of day-to-day experiences. The programme intends to help adolescents improve their ability to describe internal and external developments by reducing anxiety, avoiding spontaneous, impulsive behaviour, and improving the ability to regulate their emotions (Semple \& Lee, 2011). Intervention was performed within the framework of this study by translating and approbating the experimental MBCT$\mathrm{C}$ programme within a group of early adolescents, comparing changes in school anxiety and emotional regulation scores before, during, and after the experiment.

The need for school anxiety and emotional regulation interventions for children experiencing difficulties in regulating emotions and school anxiety was indicated by a study on problems related to student behaviour and emotional regulation difficulties in the early adolescence group. A total of 12 tests were conducted to test the hypothesis that school anxiety among pupils would decrease, and emotional awareness indicators would improve after the intervention programme. The results of six $6^{\text {th }}$ grade students (12 to 13 years old) were analysed within the study. The study used the Emotion Questionnaire (The Emotion Questionnaire; Rydell, Berlin, \& Bohlin, 2003; adapted by Grīvza, Brūdere-Ruska, \& Raikova, 2014), B.N. Phillips School Anxiety Questionnaire (Beeman N. Phillips, 1970, translated by Zalcmane, 2004), Parent Evaluation Questionnaire (Semple \& Lee, 2011), Children Questionnaire (Semple \& Lee, 2011).

\section{Adolescent school anxiety and emotional control difficulties}

Fear of tests and general learning difficulties cause serious emotional problems for pupils, such as increased anxiety, depression and mood swings. Studies show that anxiety caused by tests has a significant negative impact on a person's health and emotional state. Stress management mechanisms used by pupils play an important role in coping with stress. Studies show that students with high test anxiety score lower than students with low anxiety levels, and lower test scores can also be observed in situations where there is a high chance that the pupil will be assessed (Spielberg \& Vagg, 1995). Anxiety related to performance at school or satisfying the expectations or demands of parents and teachers can be so common that academic performance has deteriorated and, as a result, anxiety has increased (Škuškovnika \& Tiltiņa-Kapele, 2014). Anxious children generally show a low level of understanding of how to regulate their emotions (Daleiden \& Vasey, 1997). Adolescents with a low understanding of the diversity of emotions tend to be more anxious (Daleiden \& Vasey, 1997).

Emotional regulation is vital, because as children start studying in school, they face high expectations regarding their ability to regulate their emotions and behaviour and to develop positive relationships with their peers, thus these skills 
enable them to learn from each other and handle school tasks (Hartas, 2011). Emotion regulation, empathy and the ability to deal with anxiety are considered essential components of child development (Trentacosta, Izard, Mostow, \& Fine, 2006). High emotionality of fear and an inability to regulate fear may lead to internalised behaviour problems, while high anger emotionality and inability to regulate positive emotions may lead to externalised behaviour problems (Rydell, Berlin, \& Bohin, 2003). The ability of children to acknowledge and regulate their emotions is particularly important in interpersonal relationships; it influences their behaviour in school so that others can understand the child better (Mavriveli et al., 2009). Common signs of difficulties caused by school anxiety are lowered learning outcomes, followed by low self-esteem, which leads to doubt, uncertainty about one's ability and decreased motivation to learn, causing anger, fear, aggression (Abramova, 2003).

\section{The concept of emotion regulation}

Emotion regulation is the ability of a person to understand and accept his or her emotional experience, to manage and control negative emotions, and to be productive in times of crisis or distress (Spielberg, 1999; Krohne, 2003; Gross \& Thompson, 2006, etc.).

People with good emotion regulation abilities are capable of controlling impulsive behaviour, which helps them build social relationships, behave in an appropriate manner, be empathetic, deal with problems and cope with difficulties (Landy, 2009).

Emotion regulation, empathy and the ability to deal with anxious emotions are considered essential components of child development (Trentacosta, Izard, Mostow, \& Fine, 2006). A study on children's emotion regulation found that high emotionality of fear and an inability to regulate fear may lead to internalised behaviour problems (the child becomes anxious and/or depressed, closes down and complains about physical health problems such as pain, dizziness, indigestion, etc.), while high anger emotionality and an inability to regulate positive emotions may lead to externalised behaviour problems (the child is provocative, impulsive, hyperactive) (Rydell, Berlin, \& Bohin, 2003).

Emotion regulation is an essential skill which is vital for developing positive relationships with peers, maintaining good relationships and improving social skills (Blair et al., 2015). The child's ability to regulate his or her inner emotions determines their future socio-emotional development. This study shows individual differences in their development. The ability to effectively regulate emotions offers children greater opportunities to actively and positively participate in social interactions that help develop collaboration, communication, and self-confidence (Blair et al., 2015). 
Kalnciema \& Svence, 2020. Changes in School Anxiety and Emotional Self-Regulation of an Adolescence Experimental Group Following the ABKT-B Programme

R.D. Lane (2000) says that emotion regulation is the ability to recognise and describe one's own and others' emotions, and to distinguish one's emotions from others' emotions by naming and describing different types of emotional experiences (Bajgar et al., 2005).

\section{Description of the school anxiety and emotion regulation correction programme}

MBCT-C is adapted to school-age children and pays attention to a number of developmental features (Semple \& Lee, 2011).

The main goal of the programme is to improve attention and concentration, promote self-regulation of emotions and practice awareness. Practising awareness helps you manage stressful situations and offers other ways to respond to events. Practising awareness lets one understand how thoughts and feelings affect our experience. Developing thoughts, feelings and bodily sensations through awareness practices helps a person feel like they are present. As children become more self-aware and aware of their surroundings, they often choose to respond to stressful situations with greater understanding and emotional stability (Semple \& Lee, 2011).

Awareness-based cognitive therapy for children is designed as a twelveweek programme to reduce symptoms of anxiety and regulate emotions. During the practice, the child learns to be present and not worry about the past or future. By being more aware, the child can find other ways of reacting to or behaving in anxious and stressful situations. This freedom of choice creates a sense of release, which in turn helps children to respond appropriately to autopilot situations. MBCT-C helps develop and understand the relationship between thoughts and feelings, including anxious thoughts and feelings. MBCT-C techniques include simple breathing exercises, practices oriented at the five senses (smell, taste, touch, vision, hearing), and body scanning practices. It helps children become aware of how anxiety symptoms manifest themselves in thoughts, feelings, sensations and behaviour (Semple \& Lee, 2011).

MBCT-C is a specifically developed programme for children, adapted from two awareness programmes aimed at adults. These programmes are based on many years of psychology research, which confirm their effectiveness and usefulness. It is a part of the Mindfulness-Based Stress Reduction programme, developed in 1979 by John Kabat-Zinn and his colleagues at the Stress Reduction and Relaxation Program at the University of Massachusetts Medical Center, which is the oldest and largest such institution in the world. MBCT helps control stress-related disorders and is effective against a variety of psychological disorders. The programme lasts eight weeks and includes daily homework (KabatZinn, 1994) and conscious cognitive therapy. This programme was created and 
developed by Zindel Segal, Mark Williams and John Teasdale. MBCT is based on numerous psychology studies and is designed to prevent the risk of recurring episodes of depression. It helps adults see patterns in their daily behaviour and thoughts, identifying bad moods and negative thoughts. The programme lasts for eight weeks and involves daily homework (Williams, Teasdale, Segal, \& KabatZinn, 2007)

MBCT-C (Semple \& Lee, 2011) consists of weekly 90-minute sessions. Frequent repetition of practice reinforces the effect. Each session of the children's programme starts off with a short meditation session, followed by a review of the previous week's session, and then the work and exercises performed at home are discussed in a group. The programme teaches the child to practice understanding his or her daily experiences and provides a variety of meditation practices, including breath awareness, body awareness (body scanning) and motion awareness (simple yoga postures). These exercises are discussed after each experience by focusing on the thoughts, feelings, and sensation.

The methods used within the MBCT-C programme are designed to be participatory and interactive, offering a variety of experiences. Experimental learning exercises focus on understanding in a specific sensory way, such as conscious vision, hearing, sensation, taste and smell. The MBCT-C programme is also designed in a way that makes the child's parents an integral part of the programme. Family involvement in treatment has been shown to improve study outcomes, as children spend more time with their families than adults outside the home (Kaslow \& Racusin, 1994).

Several studies suggest that MBCT can significantly reduce relapse rates in patients with a history of three or more episodes of depression (Eisendrath et al., 2008; Kenny \& Williams, 2007; Kingston, Dooleys, Betes, Lawlor, \& Malone, 2007; Kuyken et al., 2008; Ma \& Teasdale, 2004; Ree \& Craigie, 2007; Teasdale et al., 2000; Williams, Duggan, Williams, Teasdale, Segal, \& Soulsby, 2000). MBCT has been shown to provide protection against depressive relapse with pharmacotherapy (Segal et al., 2010). Studies were conducted using MBCT to treat patients with eating disorders (Baer, Fischer, \& Huss, 2005), generalised anxiety disorder (Evans et al., 2008), treatment-resistant depression (Eisendrath et al., 2008), anxiety (Finucane \& Mercer, 2006), bipolar disorder (Williams et al., 2008), anxiety and insomnia (Yook et al., 2008), and primary insomnia (Heidenreich, Tuin, Pflug, Michal, \& Michalak, 2006).

\section{Studies on MBCT programmes}

A number of studies suggest that meditation techniques can be helpful in reducing anxiety symptoms in school-age children (Chang \& Hiebert, 1989; Dacey \& Fiore, 2000; Fish, 1988; Humphrey, 1988; Rozman, 1976). However, 
Kalnciema \& Svence, 2020. Changes in School Anxiety and Emotional Self-Regulation of an Adolescence Experimental Group Following the ABKT-B Programme

there are few published studies demonstrating the usefulness and effectiveness of child awareness practices. Linden (1973) studied the impact of meditation practice in school on adolescent cognitive and affective aspects. Linden hypothesised that meditation practice can help adolescents learn to concentrate and change their sensory states by deliberately shifting attention. The results of the study showed that adolescents who completed 18 weeks of meditation practice were less anxious about getting tested.

Semple, Reid \& Miller (2005) conducted a study to test the usefulness of practising child awareness during the learning process. A 6-week study was conducted involving five anxious children aged 10 to 12 years. The results of the study showed that the programme was child-friendly and could be implemented in the school environment. The children were able to understand the concept of awareness, to use the exercises and practices learned in the programme, and to integrate awareness into their daily lives. The authors concluded that the awareness intervention programme is effective in reducing anxiety in children.

There is an extensive body of literature on adult awareness, but there are only a few studies on how to use awareness-based therapy in children.

Mindfulness-Based Cognitive Therapy for Children (MBCT-C) is based on the assumption that it is better for children to be more aware of their thoughts, feelings and body sensations. The MBCT-C programme is aimed at helping children distinguish between reasoning and describing to develop the ability to describe internal and external events without giving in to spontaneous, impulsive behaviour triggered by an experience. By practising mindfulness on a regular basis, the child can change his or her usual reactions and actions in response to events and promote greater awareness regarding how to respond (or not to respond) to events with greater awareness. Understanding emotion regulation can enhance a child's ability to respond to anxious thoughts, accept strong emotions, and manage unpredictable situations (Semple \& Lee, 2011).

According to Beck (1976), MBCT-C helps a child identify and recognise bias, recognise that thoughts influence emotions and behaviours, distance themselves from illusions, and develop more realistic ways of self-expression, while De Silva (1985) argues that consciousness-based methods promote behavioural change.

The programme is aimed at changing thoughts, emotions, behaviour. Misinterpretation of events and reliving stressful situations in one's head play a large role in anxiety situations (Piacentini \& Bergman, 2001).

Anxious children usually display a poor understanding of the variability of emotions and their regulation (Daleiden \& Vasey, 1997). Particularly anxious children sometimes have difficulty distinguishing their emotions from reality (Barlow, 2002). 
In recent years, there has been growing interest in innovative intervention methods for children that encourage the use of meditation practices, increasing awareness of thoughts, feelings, and bodily sensations (Segal, Willams, \& Teasdale, 2002).

A number of studies suggest that meditation techniques can be helpful in reducing anxiety symptoms in school-age children (Chang \& Hiebert, 1989; Dacey \& Fiore, 2000; Fish, 1988; Humphrey, 1988; Rozman, 1976; Smith \& Wolmack, 1987).

\section{Study procedure}

Within the analysis of changes in pupil emotion regulation and school anxiety indicators, we compared indicators in the experimental and control group. The indicators were measured in two steps: $\mathrm{T} 1$ at the start of the intervention programme, $\mathrm{T} 2$ at the end of the intervention programme after 12 intervention sessions.

To provide more individualised attention to children, the group consisted of six to eight participants. Latvian-speaking children aged 12 to 13 , or $6^{\text {th }}$ grade students, participated in the study. Relevance was determined by age, class, gender, difficulties caused by emotion regulation and school anxiety. The programme was selected based on its availability and the prevalence of school anxiety problems, which was determined by the children's need for psychological support.

All parents of children in the sixth grade $(n=21)$ were involved and informed at the start of the programme. Parents were asked to sign the consent form and return it with information on whether they would be interested in participating in the study. A total of 12 consent forms were returned. Six children withdrew from the first assessment, five due to time conflicts with other activities $(n=5)$, while one child was excluded because of age. In the end, 6 children were included in the experimental group.

In order to participate in the study, participants had to attend and participate in at least $80 \%$ of the sessions, which meant attending 10 or more of these sessions over a period of 12 weeks.

Group participants $(n=6)$ were selected by age, class, gender, difficulties caused by emotion regulation and school anxiety.

School anxiety indicators. Cronbach's alpha for school anxiety scores: general anxiety at school $=0.70$, frustration of need for success $=0.78$, fear of self-expression $=0.74$, fear of knowledge test $=0.73$, fear of not meeting the expectations of others $=0.74$, low physiological resistance to stress $=0.80$, problems and fears teachers $=0.79$, total alarm level $=0.78$ (Zalcmane, 2004). The results indicate statistically significant differences between pre- and post- 
Kalnciema \& Svence, 2020. Changes in School Anxiety and Emotional Self-Regulation of an Adolescence Experimental Group Following the ABKT-B Programme

experiment school anxiety indicators and indicate the potential effectiveness of the intervention on school anxiety scores - the experimental group's school anxiety scores improved compared to the control group, while the results of the control group worsened (see Table 1).

Table 1 Results of the t-Test for school anxiety intensity in control and experimental groups before intervention (T1) and after 12 intervention sessions (T2)

\begin{tabular}{|c|c|c|c|c|c|c|c|c|}
\hline \multirow[t]{2}{*}{ Variables } & & \multicolumn{2}{|c|}{$\begin{array}{l}\text { Control group } \\
\text { total }(n=6)\end{array}$} & \multicolumn{2}{|c|}{$\begin{array}{c}\text { Experimental } \\
\text { group total } \\
(n=6)\end{array}$} & \multirow[t]{2}{*}{$t$} & \multirow[t]{2}{*}{$p$} & \multirow[t]{2}{*}{$\begin{array}{l}\text { Effect } \\
\text { size d' }\end{array}$} \\
\hline & & $M$ & $S D$ & $M$ & $S D$ & & & \\
\hline \multirow{2}{*}{$\begin{array}{l}\text { General anxiety in } \\
\text { school }\end{array}$} & $\mathrm{T} 1$ & 8.00 & 4.42 & 7.83 & 6.11 & 0.54 & 0.96 & 0.03 \\
\hline & $\mathrm{T} 2$ & 11.00 & 3.16 & 4.50 & 5.21 & $2.61 *$ & 0.03 & 1.65 \\
\hline \multirow{2}{*}{$\begin{array}{l}\text { Frustration caused } \\
\text { by the need to } \\
\text { succeed }\end{array}$} & $\mathrm{T} 1$ & 2.83 & 1.47 & 2.67 & 1.37 & 0.20 & 0.84 & 0.13 \\
\hline & $\mathrm{T} 2$ & 4.83 & 1.72 & 2.17 & 1.33 & $3.00 *$ & 0.01 & 1.90 \\
\hline \multirow{2}{*}{$\begin{array}{l}\text { Fear of self- } \\
\text { expression }\end{array}$} & $\mathrm{T} 1$ & 2.33 & 1.37 & 2.17 & 0.75 & 0.26 & 0.80 & 0.17 \\
\hline & $\mathrm{T} 2$ & 3.50 & 0.84 & 2.83 & 1.47 & 0.96 & 0.36 & 0.61 \\
\hline \multirow{2}{*}{$\begin{array}{l}\text { Fear of knowledge } \\
\text { testing }\end{array}$} & $\mathrm{T} 1$ & 1.83 & 0.98 & 2.00 & 1.67 & 0.21 & 0.84 & 0.13 \\
\hline & $\mathrm{T} 2$ & 3.83 & 0.75 & 1.00 & 1.10 & $\begin{array}{l}5.20 * \\
*\end{array}$ & 0.00 & 3.30 \\
\hline \multirow{2}{*}{$\begin{array}{l}\text { Fear of not } \\
\text { meeting } \\
\text { expectations of } \\
\text { other people }\end{array}$} & $\mathrm{T} 1$ & 2.33 & 1.21 & 2.00 & 1.10 & 0.50 & 0.63 & 0.32 \\
\hline & $\mathrm{T} 2$ & 3.00 & 0.89 & 1.33 & 0.82 & $\begin{array}{l}0.37 * \\
*\end{array}$ & 0.01 & 2.13 \\
\hline \multirow{2}{*}{$\begin{array}{l}\text { Low physiological } \\
\text { resistance to stress }\end{array}$} & $\mathrm{T} 1$ & 1.33 & 1.03 & 1.50 & 1.05 & 0.28 & 0.79 & 0.18 \\
\hline & $\mathrm{T} 2$ & 1.33 & 1.03 & 0.83 & 0.75 & 0.96 & 0.36 & 0.61 \\
\hline \multirow{2}{*}{$\begin{array}{l}\text { Problems and fears } \\
\text { in relationships } \\
\text { with teachers }\end{array}$} & $\mathrm{T} 1$ & 2.67 & 1.21 & 3.17 & 1.60 & 0.61 & 0.56 & 0.39 \\
\hline & $\mathrm{T} 2$ & 4.00 & 1.26 & 1.67 & 1.03 & $\begin{array}{l}3.50 * \\
*\end{array}$ & 0.01 & 2.21 \\
\hline \multirow{2}{*}{ Total anxiety } & $\mathrm{T} 1$ & 17.16 & 5.98 & 17.83 & 9.24 & 0.15 & 0.89 & 0.09 \\
\hline & $\mathrm{T} 2$ & 23.50 & 5.12 & 12.83 & 8.01 & $2.74 *$ & 0.02 & 1.74 \\
\hline
\end{tabular}

Note. Legend: $M$ is the arithmetic mean, $S D$ is the standard deviation, $t$ is the student's t-criterion value for independent groups, $T 1$ is the result at the start of the intervention programme, $T 2$ is the result after 12 intervention sessions. ${ }^{*} p<0.05, * * p<0.01, d^{\prime}-$ effect size (Cohen, 1988).

The results in Table 1 indicate that all school anxiety scores were similar for the two groups before the intervention and did not show statistically significant differences. However, after the intervention, both the total anxiety level and other anxiety scores for the experimental and control groups showed statistically significant differences. 
Therefore, it can be concluded that an intervention programme helps reduce school anxiety levels or prevents the scores from worsening, as observed in the control group.

Emotion regulation indicators. Authors' Surveys for Kronbach's Alpha Emotion Control Indicators; anger $=0.79$, fear $=0.72$, and positive emotion/excitement $=0.69$ (Rydell, Berlin, \& Bohlin, 2003). The results in Table 2 indicate that all emotion regulation scores were similar for the experimental and control groups before the intervention (T1), and no statistically significant differences were observed between the groups. Significant differences between the experimental and control group emotion regulation scores were observed following the intervention (T2).

Table 2 Results of the t-Test for emotion regulation in control and experimental groups before intervention (T1) and after 12 intervention sessions (T2)

\begin{tabular}{|c|c|c|c|c|c|c|c|c|}
\hline \multirow[t]{2}{*}{ Variables } & \multicolumn{3}{|c|}{$\begin{array}{l}\text { Control group } \\
\text { total }(n=6)\end{array}$} & \multicolumn{2}{|c|}{$\begin{array}{c}\text { Experimental } \\
\text { group total } \\
(n=6)\end{array}$} & \multirow[t]{2}{*}{$t$} & \multirow[t]{2}{*}{$P$} & \multirow[t]{2}{*}{$\begin{array}{l}\text { Effect } \\
\text { size d' }\end{array}$} \\
\hline & & $M$ & $S D$ & $M$ & $S D$ & & & \\
\hline \multirow{2}{*}{$\begin{array}{l}\text { Anger-emotion } \\
\text { regulation }\end{array}$} & $\mathrm{T} 1$ & 2.72 & 0.82 & 2.11 & 0.62 & 1.45 & 0.18 & 0.92 \\
\hline & $\mathrm{T} 2$ & 2.38 & 0.80 & 1.14 & 0.34 & $2.26 *$ & 0.03 & 1.68 \\
\hline \multirow{2}{*}{$\begin{array}{l}\text { Fear-emotion } \\
\text { regulation }\end{array}$} & $\mathrm{T} 1$ & 2.22 & 0.58 & 2.00 & 0.92 & 0.50 & 0.63 & 0.32 \\
\hline & $\mathrm{T} 2$ & 1.88 & 0.54 & 1.44 & 0.50 & 1.47 & 0.17 & 0.93 \\
\hline \multirow{2}{*}{$\begin{array}{l}\text { Excitement- } \\
\text { emotion regulation }\end{array}$} & $\mathrm{T} 1$ & 2.55 & 0.40 & 2.00 & 0.92 & 1.36 & 0.21 & 0.86 \\
\hline & $\mathrm{T} 2$ & 2.38 & 0.38 & 1.33 & 0.56 & $3.80 * *$ & 0.00 & 2.40 \\
\hline \multirow{2}{*}{$\begin{array}{l}\text { Total emotion } \\
\text { regulation }\end{array}$} & $\mathrm{T} 1$ & 2.50 & 0.52 & 2.03 & 0.69 & 1.31 & 0.22 & 0.83 \\
\hline & $\mathrm{T} 2$ & 2.22 & 0.49 & 1.40 & 0.38 & $3.20 * *$ & 0.01 & 2.03 \\
\hline
\end{tabular}

Note. Legend: $M$ is the arithmetic mean, $S D$ is the standard deviation, $t$ is the student's $t$-criterion value for independent groups, $\mathrm{T} 1$ is the result at the start of the intervention programme, T2 is the result after 12 intervention sessions. ${ }^{*} p<0.05, * * p<0.01, d^{\prime}-$ effect size (Cohen, 1988).

Theoretical studies show that anxious children usually display a poor understanding of the variability of emotions and their regulation (Daleiden \& Vasey, 1997). Particularly anxious children sometimes have difficulty distinguishing their emotions from reality (Barlow, 2002).

Pupil survey following intervention. The participant's questionnaire assesses the pupil's overall experience with the programme. Participant assessment of the programme demonstrates the usefulness and effectiveness of the programme based on a number of positive responses received about the programme. 
Kalnciema \& Svence, 2020. Changes in School Anxiety and Emotional Self-Regulation of an Adolescence Experimental Group Following the ABKT-B Programme

These results are supported by the study described in the theoretical part which indicates that meditation practices influence cognitive and affective aspects in adolescents, helping them learn how to concentrate and change sensory states by deliberately shifting attention (Linden, 1973).

Awareness-based intervention programmes help early adolescent students develop and manage responses to stress and anxiety situations without attempting to control those events (Baer, 2003).

Parent survey following intervention. The parent survey measures parents' experience with the programme and their perception of any behavioural changes in their children. Parents' positive assessment of the programme demonstrates the usefulness and effectiveness of the programme based on a number of responses received.

The results are also supported by the study described in the theoretical part which suggests that awareness-based intervention programmes can reduce the internalisation of adolescent problems (Lee, Semple, Rosa, \& Miller, 2006; Zylowska et al., 2008).

\section{Discussion}

Having conducted the study, the author concludes that the MBCT-C intervention programme (based on Randy J. Semple and Jennifer Lee's Mindfulness-Based Cognitive Therapy for Anxious Children, 2011) helps adolescents learn to regulate their emotions and reduce school anxiety levels, or proactively helps students prevent deterioration of school anxiety indicators, as observed in the control group.

These results are also supported by a study reviewed in the theoretical section, which indicates that mindfulness-based intervention programs help early adolescent students manage reactions in stress and anxiety situations (Baer, 2003).

A limitation of the study was the relatively small study samples that do not represent the population as a whole.

The authors believe that it is important to use a science and research-based programme that is appropriate for students in connection with school anxiety and emotion regulation. Thus, the contribution of this study to Latvia's psychology field is the approbation of a new intervention programme, its summary and description.

\section{References}

Abramova, G.(2003). Prakticeskaja psihologija. Moskva: Akadem Projekt.

Baer, R.A., Fischer, S., \& Huss, D.B. (2005). Mindfulness-based cognitive therapy applied to binge eating: A case study. Cognitive and Behavioral Practice, 12, 351-358. 
Bajgar, J., Chiarrochi, J., Lane, R., \& Deane, F.P. (2005). Development of the Levels of Emotional Awareness Scale for Children (LEAS-C). British Journal of Developmental Psychology, 23, 569-586.

Beck, A.T. (1976). Cognitive therapy and the emotional disorders. NY: International Universities Press.

Blair, B.L., Perry, N.B., O’Brein, M., Calkins, S.D., Keane, S.P., Shanahan, L. (2015). Identifying Developmental Cascades among Differentiated Dimensions of Social Competence and Emotion Regulation. Developmental Psychology, 51, 8, 1062-1073.

Chang, J., \& Hiebert, B. (1989). Relaxation procedures with children: A review. Medical Psychotherapy, 2, 163-176.

Dacey, J.S., \& Fiore, L.B. (2000). Your anxious child. San Francisco: Jossey-Bass.

Daleiden, E.L., \& Vasey, M.W. (1997). An information-processing perspective on childhood anxiety. Clinical Psychology Review, 17, 407-429.

De Silva, P. (1985). Early Buddhist and modern behavioral strategies for the control of unwanted intrusive cognitions. Psychology Record, 35, 437-443.

Eisendrath, S.J., Delucchi, K., Bitner, R., Fenimore, P., Smit, M., \& McLane, M. (2008). Mindfulness-based cognitive therapy for treatment-resistant depression: A pilot study. Psychotherapy and Psychosomatics, 77, 319-320.

Evans, S., Ferrando, S., Findler, M., Stowell, C., Smart, C., \& Haglin, D. (2008). Mindfulnessbased cognitive therapy for generalized anxiety disorder. Journal of Anxiety Disorders, 22, 716-721.

Finucane, A., \& Mercer, S.W. (2006). An exploratory mixed methods study of the acceptability and effectiveness of mindfulness-based cognitive therapy for patients with active depression and anxiety in primary care. BMC Psychiatry, 6.

Fish, M.C. (1988). Relaxation training for childhood disorders. In C.E. Schaefer (Ed.), Innovative interventions in child and adolescent therapy (pp. 160-192). NY: Wiley.

Flook, L., Smalley, S.L., Kitil, M.J., Galla, B.M., Kaiser, Greenland, S., Locke, J., Ishijima, E., \& Kasari, C. (2015). Effects of Mindful Awareness Practices on Executive Functions in Elementary School Children. Journal of Applied School Psychology, 26(1), 70-95.

Gross, J.J., \& Thompson, R.A. (2006). Emotion regulation: Conceptual foundations. In J. Gross (Ed.), Handbook of emotion regulation. New York.

Hartas, D. (December, 2011). The ecology of young children's behaviour and social competence; child characteristics, socio-economic factors and parenting. Oxford Review of Education, 37(6), 763-783.

Heidenreich, T., Tuin, I., Pflug, B., Michal, M., \& Michalak, J. (2006). Mindfulness-based cognitive therapy for persistent insomnia: A pilot study. Psychotherapy and Psychosomatics, 75, 188-189.

Humphrey, J.H. (1988). Teaching children to relax. Springfield, IL: Charles C Thomas.

Kabat-Zinn, J. (1994). Wherever you go, there you are: Mindfulness meditation for everyday life. New York: Hyperion.

Kaslow, N.J., \& Racusin, G.R. (1994). Family therapy for depression in young people. In W.M. Reynolds \& H.F.J ohnston (Eds.), Issues in clinical child psychology. Handbook of depression in children and adolescents (pp. 345-363). New York, NY, US: Plenum Press.

Kenny, M.A., \& Williams, J.M.G. (2007). Treatment-resistant depressed patients show a good response to mindfulness-based cognitive therapy. Behaviour Research and Therapy, 45, 617-625. 
Kalnciema \& Svence, 2020. Changes in School Anxiety and Emotional Self-Regulation of an Adolescence Experimental Group Following the ABKT-B Programme

Kingston, T., Dooley, B., Bates, A., Lawlor, E., \& Malone, K. (2007). Mindfulness-based cognitive therapy for residual depressive symptoms. Psychology and Psychotherapy: Theory, Research and Practice, 80, 193-203.

Klatt, M., Harpster, K., Browne, E., White, S., \& Case-Smith, J. (2013). Feasibility and preliminary outcomes for Move-Into-Learning: An arts-based mindfulness classroom intervention, The Journal of Positive Psychology.

Krohne, H.W. (2003). Individual differences in emotional reactions and coping. In R.J. Davidson, K.R. Scherer, H.H. Goldsmith (Eds.), Handbook of affective sciences (pp. 698-725). New York: Oxford University Press.

Kuyken, W., Byford, S., Taylor, R.S., Holden, E., Barrett, B., Evans, A., et al. (2008). Mindfulness-based cognitive therapy to prevent relapse in recurrent depression. Journal of Consulting and Clinical Psychology, 76, 966-978.

Landy, S. (2009). Pathways to Competence. Encouraging Healthy Social and Emotional Development in Young Children. Paul H. Brookes Publishing, Baltimore, Maryland.

Lane, R.D. (2000). Levels of Emotional Awareness: Neurobiological, psychological and social perspectives. In R. Bar-On \& J.Parker (Eds.), Handbook of emotional intelligence. Theory, development, assessment and application at home, school, and in the workplace (pp. 171-191). San Francisko: Jossey Bass.

Linden, W. (1973). Practicing of meditation by school children and their levels of field dependence-independence, anxiety. Journal of Consulting and Clinical Psychology, 41.

Ma, H.S., \& Teasdale, J.D. (2004). Mindfulness-based cognitive therapy for depression: Replication and exploration of differential relapse prevention effects. Journal of Consulting and Clinical Psychology, 72, 31-40.

Mavroveli, S., Petrides, K.V., \& Sangareau, Y. (2009). Exploring the relationships between trait emotional intelligence and objective socio-emotional outcomes in childhood. British Journal of Educational Psychology, 79.

Napoli, M., Krech, P.R., \& Holley, Lc.C. (2005). Mindfulness Training for Elementary School Students. Journal of Applied School Psychology, 21.

Ree, M.J., \& Craigie, M.A. (2007). Outcomes following mindfulness-based cognitive therapy in a heterogeneous sample of adult outpatients. Behaviour Change, 24, 70-86.

Rozman, D. (1976). Meditating with children: A workbook on new age educational methods using meditation. Boulder Creek, CA: U Trees Press.

Rydell, A.M., Berlin, L., \& Bohlin, G. (2003). Emotionality, Emotion Regulation, and Adaptation Children. Emotion, 3(1), 30-47.

Schonert-Reichl, K.A., \& Lawlor, M.S. (2010). The Effects of a Mindfulness-Based Education Program on Pre- and Early Adolescents' Well-Being and Social and Emotional Competence. Mindfulness, 1, 137-151.

Semple, R.J., Reid, E.F.G., \& Miller, L.F. (2005). Treating anxiety with mindfulness: An open trial of mindfulness training for anxious children. Journal of Cognitive Psychotherapy, 19, 387-400.

Semple, R.J., \& Lee, J. (2011). Mindfulness-based cognitive therapy for anxious children: A manual for treating childhood anxiety. Oakland, CA: New Harbinger.

Semple, R.J., Lee, J., \& Miller, L. (2006). Mindfulness-based cognitive therapy for children. In R. Baer (Ed.). Mindfulness-based treatment approaches: Clinician's guide to evidence base and applications (pp. 143-166). San Diego, CA: Elsevier.

Southam-Gerow, M.A., \& Kendall, P.C. (2000). A preliminary study of the emotion understanding of youths referred for treatment of anxiety disorders. Journal of Clinical Child Psychology, 29, 319-327. 
Spielberger, C.D., \& Vagg, P. (1995). Test Anxiety: a transactional process model. In C.D. Spielberger, P. Vagg (Eds.). Test Anxiety. Theory, Assessment, and Treatment. New York: Taylor \& Francis.

Škuškovnika, D., Tiltiņa-Kapele, I., \& Dudkina, A. (2014). Trauksme un agresija. Korekcijas iespējas. Zinātne.

Teasdale, J.D., Segal, Z.V., Willams, J.M.G., Redgeway, V.A., Soulsby, J.M., \& Lau, M. (2000). Prevention of relapse/recurrence in major depression of mindfulnessbased cognitive therapy. Journal of Consulting and Clinical Psychology, 79.

Trentacosta, C.J., Izard, C.E., Mostow, A.J., \& Fine, S.E. (2006). Children’s Emotion and Attentional Competence in Early Elementary School. School Psychology Quarterly, 21(2), 148-170.

Williams, J.M.G., Alatiq, Y., Crane, C., Barhofer, T., Fennell, M.J.V., Duggan, D.S., et al. (2008). Mindfulness-based cognitive therapy (MBCT) in bipolar disorder: Preliminary evaluation of immediate effects on between-episode functioning. Journal of Affective Disorders, 107, 275-279.

Willams, J.M.G., Duggan, D.S., Crane, C., \& Fennell, M.J.V. (2006). Mindfulness-based cognitive therapy for prevention of recurrence of suicidal behaviour. Journal of Clinical Psychology, 62, 201-210.

Willams, J.M.G., Teasdale, J.D., Segal, Z.V., \& Soulsby, J. (2007). Mindfulness-based cognitive therapy reduces overgeneral autobiographical memory in formerly depressed patients. Journal of Abnormal Psychology, 109.

Yook, K., Lee, S.-H., Ryu, M., Kim, K.-H., Choi, T.K., et al. (2008). Usefulness of mindfulness-based cognitive therapy for treating insomnia in patients with anxiety disorders: A pilot study. Journal of Nervous and Mental Disease, 196, 501-503.

Zylowska, L., Ackermann, D.L., Yang, M.H., Futrell, J.L., Horton, N.L., Hale, S., et al. (2007). Mindfulness meditation training in adults and adolescents with ADHD. A feasibility study. Journal of Attention Disorders. 